\title{
Maxillary central incisor dimensions and its association with lower anterior facial height
}

Rajesh Gyawali, Varun Pratap Singh

Shri Jagdishprasad Jhabarmal Tibrewala University, Jhunjhunu, Rajasthan, India

\section{Correspondence}

Dr. Rajesh Gyawali

Phd Scholar,

Shri Jagdishprasad Jhabarmal

Tibrewala University,

Jhunjhunu, Rajasthan, India

\section{Email:}

gyawalirajesh@gmail.com

DOI: http://

dx.doi.org/10.3126/

jemsn.v12i3.15477

Article received: June $20^{\text {th }}$

2016

Article accepted: Aug $26^{\text {th }}$

2016

\begin{abstract}
Background \& Objectives: Maxillary anteriors are the major teeth displayed during the smile and have a dominant role in the dentofacial appearance. As the dimensions of incisors vary with various facial dimensions, this study aimed to find out the ratio of width to height of the maxillary central incisor and correlate it with the lower anterior facial height. Materials \& Methods: One hundred participants (50 male and 50 female) were enrolled in this study. The width-height ratio of maxillary central incisor was calculated by measurements made in the photographs with Image $J$ software. Lower anterior facial height was measured as the distance between subnasale and lower border of the chin with the help of digital vernier caliper. Correlation between width-height ratio and lower anterior facial height was done with Pearson's correlation. Results: The width height ratio of maxillary central incisor was found to be 0.86 for male and 0.89 for female. This ratio was statistically insignificant when compared between gender and sides. There was negligible correlation between this ratio and lower anterior facial height. Conclusion: Mean Width-height ratio of maxillary central incisor obtained from this study would serve as a guide in esthetic enhancement of the maxillary anterior dentition.

Key words: Esthetics, Lower anterior facial height, Maxillary central incisor, Proportion, Width-Height ratio
\end{abstract}

Citation: Gyawali R, Singh VP. Maxillary central incisor dimensions and its association with lower anterior facial height. JCMS Nepal. 2016;12(3):118-22.

\section{INTRODUCTION}

With increasing public awareness of esthetics, dental professionals are findings ways to improve the appearance of the teeth which in turn add beauty to the face. Maxillary anteriors are the teeth mostly displayed during the smile and play an important role in the overall facial esthetics and influence the social attractiveness. ${ }^{1}$ Besides their alignment; the shape, size, colour and symmetry of the maxillary anteriors are important considerations to the clinician. $^{2}$ As maxillary central incisors occupy $50 \%$ of the apparent dimension of all the anteriors, it has dominant effect in the smile esthetics. ${ }^{3}$

The width height ratio of maxillary incisors has been widely studied to harmonize it with the smile. It is believed to play a vital role in the esthetic outcome of the maxillary anterior teeth. As mesiodistal dimension is relatively stable, widthheight ratio of a tooth often serves as a guide in restoration of reduced crown height due to trauma or attrition. Hence, this ratio is quite important for restorative planning, prosthetic replacement, esthetic gingival surgical procedure, and during finishing stage of orthodontic treatment. In search for an ideal ratio, several authors proposed various ratios- $0.72,{ }^{4} 0.76,{ }^{5} 0.78,{ }^{4,6} 0.79,{ }^{7} 0.80,{ }^{8} 0.85,{ }^{9} 0.85$ $-0.86,{ }^{10} 0.89-0.91 .^{11}$

Many studies had correlated the dimensions of maxillary incisors with the inter-pupillary distance, inter-canthal distance, inter-alar distance, intercommisural width, and bizygomatic width. ${ }^{12}$ Less emphasis has been given in the vertical dimension of face when correlating it with the dimensions of central incisor. This study aimed to find out the ratio of width to height of the maxillary central incisor in a Nepalese sample and correlate it with the lower anterior facial height.

\section{MATERIALS AND METHODS}

Ethical clearance to undertake this research has been obtained from NHRC (Nepal Health Research Council). A sample of 100 (50 males and 50 females) participants were enrolled in this study. The inclusion criteria were Class I molar relation, 
class I canine relation with well aligned maxillary central incisors, no midline diastema, no gingival recession, no gingival inflammation and no attrition of the incisal edge as seen clinically. They were excluded if they had undergone prior orthodontic or restorative therapy involving maxillary central incisor. Informed consent was obtained from all the participants prior to the enrollment.

Lower anterior facial height was measured as the distance between subnasion and the lowermost border of the soft tissue chin. It was measured with a digital caliper with patient seated upright in the chair with jaw in relaxed position. Each participant was asked to recline in the dental chair and intraoral frontal photograph was taken with cheeks retracted with the help of photographic retractor by single investigator (RG). A Nikon D 5100 DSLR camera was used with the lens of the camera perpendicular to the labial surface of the maxillary central incisors taking care of the rotation of patient's head. ${ }^{13}$

After the photographs were taken, they were uploaded in the computer and the dimensions of the teeth measured with the software ImageJ 1.49 (freely available at http://imagej.nih.gov/ij/). Calibration was not important as only the ratio of the dimensions of the central incisor was taken into consideration. All the data were entered in Excel 2013 and statistical analysis was done with SPSS version 20. All the measurements were made by a single investigator ( $R G)$.

Measurements of lower anterior facial height and dimensions of maxillary central incisors were repeated in randomly selected 25 samples at least two weeks from the first measurements. Descriptive statistics were calculated for all measurements along with 95\% confidence interval. Gender differences were compared with independent t-test. Correlation analysis was done to find the correlation between the width- height ratio of maxillary central incisor and the lower anterior facial height.

\section{RESULTS}

This study included 100 samples with 50 males and 50 females. The mean age was $22.23 \pm 1.99$ years. Kolmogorov-Smirnov and Shapiro-Wilk tests were done to check the distribution of lower anterior facial height and width-height ratio of maxillary central incisors. The $p$ values were above 0.05 indicating the normal distribution of these variables. Twenty-five samples were randomly selected and the lower anterior facial height as well as widthheight ratio was re-measured. Intra-class correlation coefficient was found to be 0.92 and 0.98 for widthheight ratio and lower anterior facial height respectively showing excellent reliability.

Mean WH ratio of maxillary central incisor was 0.87 and 0.88 for right and left side respectively. Paired t-test showed no statistically significant difference in the width-height ratio of maxillary central incisor between right and left side (Table 1). Hence, average of right and left sides were derived for further comparisons.

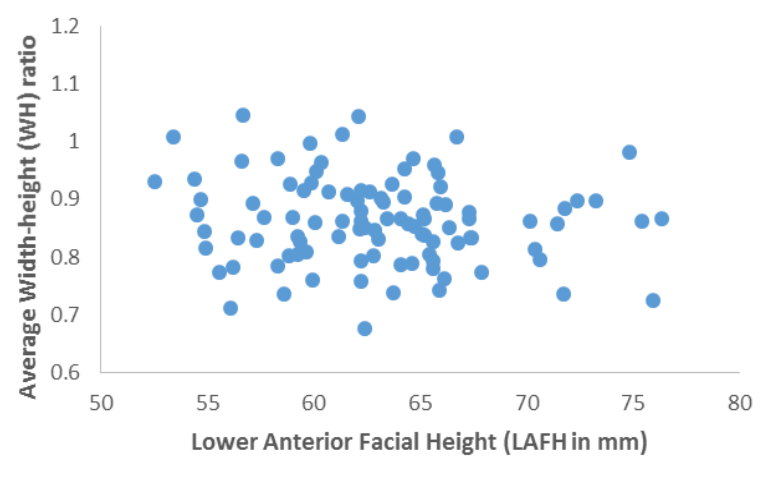

Figure 1. Scatter plot demonstrating the relationship between LAFH and WH ratio.

Mean WH ratio of maxillary central incisor was found to be 0.86 for male and 0.89 for female which is statistically insignificant difference when compared with independent sample t-test (Table 2 and 3).

Mean LAFH was $65.66 \pm 4.70 \mathrm{~mm}$ and $60.25 \pm$ $3.92 \mathrm{~mm}$ for male and female respectively showing significantly more LAFH in male than female (Table 2). The relationship between LAFH and $\mathrm{WH}$ ratio was evaluated with scatterplot (Figure 1). LAFH showed negligible correlation (Pearson's coefficient of -0.15) with $\mathrm{WH}$ ratio and there was not sufficient evidence $(p=0.142)$ to suggest this correlation as well.

\section{DISCUSSION}

This study aimed to find out the width-height ratio of maxillary central incisor and its association with lower anterior facial height. The size of maxillary central incisor has been extensively studied in extracted teeth, ${ }^{4,6}$ study models, ${ }^{14-17}$ clinically ${ }^{18}$ as 
Table 1. Paired t-test for the difference between $\mathrm{WH}$ ratio of right and left side.

\begin{tabular}{|c|c|c|c|c|c|c|c|c|}
\hline \multirow[t]{2}{*}{ Teeth } & \multirow[t]{2}{*}{ Mean } & \multirow[t]{2}{*}{ SD } & \multirow[t]{2}{*}{ SE } & \multicolumn{2}{|c|}{$95 \% \mathrm{CI}$} & \multirow[t]{2}{*}{$\mathrm{t}$} & \multirow[t]{2}{*}{ df } & \multirow[t]{2}{*}{ Sig. (2-tailed) } \\
\hline & & & & Lower & Upper & & & \\
\hline$(11-21)$ & -0.007 & 0.044 & 0.004 & -0.016 & 0.002 & -1.586 & 99 & 0.116 \\
\hline \multicolumn{4}{|c|}{ 11: Maxillary right central incisor } & \multicolumn{5}{|c|}{ SD: Standard Deviation } \\
\hline \multicolumn{4}{|c|}{ 21: Maxillary left central incisor } & \multicolumn{5}{|c|}{ SE: Standard Error of mean } \\
\hline
\end{tabular}

Table 2. Descriptive statistics for lower anterior facial height and WH ratio

\begin{tabular}{lllllllllllll}
\multicolumn{3}{c}{ Male } & \multicolumn{1}{c}{ Female } & \multicolumn{1}{c}{ Total } \\
& Mean & SD & Min & Max & Mean & SD & Min & Max & Mean & SD & Min & Max \\
LAFH & 65.66 & 4.70 & 56.20 & 76.34 & 60.25 & 3.92 & 52.52 & 70.62 & 62.95 & 5.10 & 52.52 & 76.34 \\
WH & 0.86 & 0.07 & 0.67 & 1.00 & 0.89 & 0.08 & 0.70 & 1.06 & 0.87 & 0.08 & 0.67 & 1.06 \\
ratio & & & & & & & & & & & &
\end{tabular}

LAFH: Lower anterior facial height $\quad$ WH ratio: Width-height ratio of maxillary central incisor

SD: Standard deviation

Min: Minimum

Max: Maximum

Table 3. T-test for the difference between WH ratio between male and female.

\begin{tabular}{llllllll} 
& $\mathrm{t}$ & $\mathrm{df}$ & $\begin{array}{l}\text { Sig. (2- } \\
\text { tailed) }\end{array}$ & $\begin{array}{l}\text { Mean } \\
\text { Difference }\end{array}$ & \multicolumn{2}{l}{$\begin{array}{l}\text { Std. Error } \\
\text { Difference }\end{array}$} & \multicolumn{2}{l}{$\begin{array}{l}\text { 95\% Confidence Interval } \\
\text { of the Difference } \\
\text { Lower }\end{array}$} & $\begin{array}{l}\text { Upper } \\
\text { Male-female WH }\end{array}$ & -1.850 & 98 & 0.067 & -0.028 & 0.015 & -0.059 & 0.002 \\
ratio & & & & & & &
\end{tabular}

Table 4: Comparison of WH ratio of maxillary central incisor in various population.

\begin{tabular}{|c|c|c|c|c|c|}
\hline SN & Author & Population & Male & Female & Mean MF \\
\hline 1 & Olsson et $\mathrm{al}^{\frac{5}{}}$ & Swedish & --- & --- & 0.76 \\
\hline 2 & Magne et al $\underline{6}$ & White & --- & --- & 0.78 \\
\hline 3 & Sandeep et $\mathrm{al}^{7}$ & South Indians & 0.80 & 0.79 & 0.79 \\
\hline 4 & Sterrett et al ${ }^{10}$ & Georgians & 0.85 & 0.86 & --- \\
\hline 5 & Hasanreisoglu et al $1^{11}$ & Turkish & 0.89 & 0.91 & --- \\
\hline \multirow[t]{2}{*}{6} & \multirow[t]{2}{*}{ Tsukiyama et al ${ }^{4}$} & Asian (Japanese) & --- & --- & 0.72 \\
\hline & & White (Swedish) & --- & --- & 0.78 \\
\hline 7 & Radia et al ${ }^{18}$ & British & 0.84 & 0.85 & 0.85 \\
\hline 8 & $\begin{array}{l}\text { Gyawali and Singh } \\
\text { (this study) }\end{array}$ & Nepalese & 0.86 & 0.89 & 0.87 \\
\hline
\end{tabular}

well as photographically. ${ }^{4}$ Also its dimensions have been correlated with the various facial landmarks guiding clinicians for esthetic planning of the anterior dentition.

The mean WH ratio in this study was found to be 0.86 and 0.89 for male and female respectively. The ratio was higher as compared to the study done by Olsson et al, ${ }^{5}$ Magne et al, ${ }^{6}$ Sandeep et al, ${ }^{7}$ Radia et al, ${ }^{18}$ Tsukiyama et $\mathrm{al}^{4}{ }^{4}$ whereas it is comparable with the study done by Sterrett et al, ${ }^{10}$ and Hasanreisoglu et $\mathrm{al}^{11}$ (Table 4).

Maxillary anterior teeth size varies among races and 
the gender differences is also noted as well. ${ }^{19,20}$ Males tend to have wider and longer maxillary anteriors as compared to female. ${ }^{10,11,21,22}$ This study compared the width-height ratio of maxillary central incisor, not the absolute value. The crown width-height ratio is considered as the most stable reference with less variation between the races and the genders. ${ }^{10,14,19}$ This study also showed no statistically significant difference when WH ratio was compared between male and female using ttest. Similar result was obtained when the WH ratio of maxillay central incisor was compared between sexes by Shahid et a ${ }^{14}$ in Pakistani sample, Sah et $\mathrm{al}^{16}$ in Central Chinese, Sterrett et $\mathrm{al}^{10}$ in Georgians, and Sandeep et $\mathrm{al}^{7}$ in South Indians. However, few studies discovered statistically significant difference in WH ratio of maxillary central incisor between male and female. ${ }^{17,23}$

The incisal edge of the incisors gradually show attrition with increasing age, as a result of which the clinical crown height decreases but the width is relatively stable. Knowing the ratio would guide the clinician to restore the vertical height if the width is preserved. Ideal ratio should be derived from unworn dentition as the width-height ratio significantly changes when it is measured in attrited dentition. ${ }^{4}$ This study excluded samples with significant attrition of incisal edge. Further, age of the sample was limited to 25 years which is comparable with the age range of similar reported studies. ${ }^{7,14}$

This study found negligible correlation between width-height ratio of maxillary central incisor and the lower anterior facial height. The shape and size of the incisors have been found to correlate with the various facial dimensions in the literature. Ratio of the width of the maxillary central incisor to bizygomatic width was found to be $1: 16$ by Berry, ${ }^{24}$ to interpupillary line as $1: 6.93$ by Al-Kaisy et al, ${ }^{12}$ 1:6.5 to $1: 7$ by Cesario et al, ${ }^{25} 1: 7.7$ for male and 1:7.5 for female by Hasanreisoglu et $\mathrm{al}^{11}$; to the intercanthal distance by $0.618: 226,0.267: 1 .^{27}$ Also, regression equations have been derived for the estimation of the width of central incisor taking various facial measurements. ${ }^{28}$

Similarly, investigating into the vertical dimension, Radia et $\mathrm{al}^{18}$ proposed the ratio of the height of the central incisor to the total facial height (trichion to menton) to be $1: 18$ and, to the facial height (nasion to menton) as 1:12 but only as initial guide. They further warned the deliberate application of any such ratios as strong relationship could not be verified between maxillary central incisor proportion and facial proportion. Furtado et $\mathrm{al}^{29}$ found that none of the horizontal or vertical measurements of the face could predict the dimensions of maxillary central incisor crown.

\section{CONCLUSION}

- Mean Width-height ratio of maxillary central incisor was found to be 0.86 for male and 0.89 for female.

- No statistically significant difference in width-height ratio of maxillary central incisor when compared between sides and gender.

- Negligible correlation exists between widthheight ratio of maxillary central incisor and the lower anterior facial height.

- This ratio would serve as a guide in esthetic enhancement of the maxillary anterior dentition, however psychosomatic norms of each individual should also be given priority.

\section{REFERENCES}

1. Shaw WC. The influence of children's dentofacial appearance on their social attractiveness as judged by peers and lay adults. American journal of orthodontics 1981;79(4):399-415. DOI: 10.1016/0002-9416(81)903821.

2. Bhuvaneswaran M. Principles of smile design. Journal of conservative dentistry: JCD 2010;13(4):225. DOI: 10.4103/0972-0707.73387.

3. Snow SR. Esthetic smile analysis of maxillary anterior tooth width: the golden percentage. Journal of Esthetic and Restorative Dentistry 1999;11(4):177-84. DOI: 10.1111/ j.1708-8240.1999.tb00397.x

4. Tsukiyama T, Marcushamer E, Griffin TJ, et al. Comparison of the anatomic crown width/length ratios of unworn and worn maxillary teeth in Asian and white subjects. The Journal of Prosthetic Dentistry 2012;107 (1):11-16. DOI: 10.1016/s0022-3913(12)60009-2

5. Olsson M, Lindhe J, Marinello C. On the relationship between crown form and clinical features of the gingiva in adolescents. Journal of Clinical Periodontology 1993;20 (8):570-77. DOI: 10.1111/j.1600-051x.1993.tb00773.x.

6. Magne P, Gallucci GO, Belser UC. Anatomic crown width/length ratios of unworn and worn maxillary teeth in white subjects. The Journal of prosthetic dentistry 2003;89 (5):453-61. DOI: 10.1016/s0022-3913(03)00125-2.

7. Sandeep N, Satwalekar P, Srinivas S, et al. An Analysis of Maxillary Anterior Teeth Dimensions for the Existence of Golden Proportion: Clinical Study. Journal of international oral health: JIOH 2015;7(9):18. PMID: 26435610.

8. Proffit WR, Fields Jr HW, Sarver DM. Contemporary orthodontics: Elsevier Health Sciences; 2014

9. Orozco-Varo A, Arroyo-Cruz G, Martínez-de-Fuentes R, Jiménez-Castellanos E. Biometric analysis of the clinical crown and the width/length ratio in the maxillary anterior region. The Journal of Prosthetic Dentistry 2015;113 (6):565-70. e2. DOI: 10.1016/j.prosdent.2014.11.006. 
10. Sterrett JD, Oliver T, Robinson F, et al. Width/length ratios of normal clinical crowns of the maxillary anterior dentition in man. Journal of clinical periodontology 1999;26(3):153-57. DOI: $\quad 10.1034 / j .1600$ 051x.1999.260304.x.

11. Hasanreisoglu U, Berksun S, Aras K, Arslan I. An analysis of maxillary anterior teeth: facial and dental proportions. The Journal of prosthetic dentistry 2005;94(6):530-38. DOI: 10.1016/j.prosdent.2005.10.007.

12. Neda A-K, Garib BT. Selecting maxillary anterior tooth width by measuring certain facial dimensions in the Kurdish population. The Journal of prosthetic dentistry 2015. DOI: $10.1016 /$ j.prosdent.2015.08.012.

13. Gyawali R, Pokharel PR, Giri J. Effect of Subject Rotation on Assessment of Esthetic Dental Ratios: A Simulation Study. International journal of dentistry 2016;2016. DOI: 10.1155/2016/3957806.

14. Shahid F, Alam MK, Khamis MF. Maxillary and mandibular anterior crown width/height ratio and its relation to various arch perimeters, arch length, and arch width groups. European Journal of Dentistry 2015;9 (4):490. DOI: 10.4103/1305-7456.172620.

15. Khan M, Khan MA, Hussain U. Clinical crown length, width and the width/length ratio in the maxillary anterior region in a sample of Mardan population. Pakistan Oral \& Dental Journal 2015;35(4).

16. Sah S, Zhang H, Chang T, et al. Maxillary anterior teeth dimensions and proportions in a central mainland chinese population. The Chinese Journal of Dental Research 2014;17(2):117-24.

17. Lakshmi S, Abraham A, Selvakumaran G, Sekar V, Annapoorni H. Influence of aesthetic dental and facial measurements on patient satisfaction between genders in Indian patients. Tanta Dental Journal 2015;12(3):197-202. DOI: 10.1016/j.tdj.2015.05.008.

18. Radia S, Sherriff M, McDonald F, Naini FB. Relationship between maxillary central incisor proportions and facial proportions. The Journal of prosthetic dentistry 2016. DOI: $10.1016 /$ j.prosdent.2015.10.019.

19. Gillen RJ, Schwartz RS, Hilton TJ, Evans DB. An analysis of selected normative tooth proportions. International Journal of Prosthodontics 1994;7(5).

20. Lavelle C. Maxillary and mandibular tooth size in different racial groups and in different occlusal categories. American journal of orthodontics 1972;61(1):29-37. DOI: 10.1016/0002-9416(72)90173-x

21. Richardson ER, Malhotra SK. Mesiodistal crown dimension of the permanent dentition of American Negroes. American journal of orthodontics 1975;68(2):157 -64. DOI:10.1016/0002-9416(75)90204-3.

22. İşcan MY, Kedici PS. Sexual variation in bucco-lingual dimensions in Turkish dentition. Forensic science international 2003;137(2):160-64. DOI: $10.1016 / \mathrm{s} 0379-$ 0738(03)00349-9.

23. Sitthiphan P, Viwattanatipa N, Amornvit $P$, et al. Comparison of Maxillary Anterior Teeth Crown Ratio (Width/Length) between Gender in Laotian Population. International Medical Journal 2015;22(3):199-205.

24. Berry F. Is the theory of temperaments the foundation of the study of prosthetic art. Dent Mag 1905;1(405):6.

25. Cesario VA, Jr., Latta GH, Jr. Relationship between the mesiodistal width of the maxillary central incisor and interpupillary distance. J Prosthet Dent 1984;52(5):641-3. DOI: 10.1016/0022-3913(84)90133-1.
26. Abdullah MA. Inner canthal distance and geometric progression as a predictor of maxillary central incisor

27. Al Wazzan KA. The relationship between intercanthal dimension and the widths of maxillary anterior teeth. The Journal of prosthetic dentistry 2001;86(6):608-12. DOI: 10.1067/mpr.2001.119682.

28. Scandrett FR, Kerber PE, Umrigar ZR. A clinical evaluation of techniques to determine the combined width of the maxillary anterior teeth and the maxillary central incisor. The Journal of prosthetic dentistry 1982;48(1):1522. DOI: 10.1016/0022-3913(82)90041-5.

29. Furtado GC, Furtado A, El Haje OA, et al. Relationship between the morphology of the maxillary central incisor and horizontal and vertical measurements of the face. Indian Journal of Dental Research 2014;25(2):178. DOI: 10.4103/0970-9290.135914. 